\title{
Renal Calculi as Initial Presenting Symptom of Glycogen Storage Disease (Type 1 A) in Early Infancy
}

\author{
Nida Mirza ${ }^{1}$ Smita Malhotra ${ }^{1} \quad$ Anupam Sibal $^{1}$ \\ 1 Department of Pediatric Gastroenterology, Indraprastha Apollo \\ Hospital, New Delhi, Delhi, India \\ Address for correspondence Nida Mirza, MBBS, MD, 279, First Floor, \\ South EX, Part 2 Block R, New Delhi 110049, Delhi, India \\ (e-mail: nydamirza.1@gmail.com).
}

J Child Sci 2020;00:e45-e47.

\begin{abstract}
Keywords

- renal calculi

- early infancy

- glycogen storage disease

Glycogen storage diseases are a group of heterogeneous metabolic disorders that result from a defect in enzymatic pathway of either glycogen synthesis or glycogen degradation. Here we are reporting a case of glycogen storage diseases type 1 with renal stone as initial manifestation of disease at 2 months of age. There were case reports of recurrent renal calculi in older age group with this disease and considered to be arisen due to metabolic derangements. Although the exact mechanism of renal stones in glycogen storage disease is not clear, in this unique case occurrence of renal stones at 2 months of age suggests that the pathogenesis of renal calculi is probably multifactorial or a part of disease.
\end{abstract}

\section{Introduction}

Glycogen storage diseases (GSDs) are a group of heterogeneous metabolic disorders that result from a defect in enzymatic pathway of either glycogen synthesis or glycogen degradation. Type-1 glycogen storage disease is also known as von Gierke's disease caused by deficiency of glucose-6-phosphatase (G6PD) enzyme. G6PD deficiency results in accumulation of glycogen in hepatocytes and proximal renal tubules that results in hepatomegaly and nephromegaly, respectively. Usually, disease presents with hepatomegaly, fasting hypoglycemia, lactic acidosis, hypertriglyceridemia, hyperuricemia, and/or growth retardation. Hypoglycemia may be first manifestation of disease at the time of weaning. ${ }^{1}$ Here we are reporting a case of glycogen storage diseases type 1 with renal stone as initial manifestation of disease at 2 months of age.

\section{Case}

A 10-month-old male baby born full term with $3.5 \mathrm{~kg}$ birth weight, fifth in birth order to consanguineous marriage, presented with complaints of recurrent renal calculi since 2 months of age, intermittent hematuria and also passage of stone with urine once. The neonatal period was uneventful. There was history of two episodes of abnormal movements at
6 months of age, which subsided by its own, and progressive abdominal distension was observed since 8 months of age. There was history of an elder female sibling's death suddenly at 3 months of age after excessive crying for few hours at night. The cause of her death was not known as she died before reaching hospital. The other four elder siblings were apparently normal. On examination, it was observed that the infant had doll-like facies, and protuberant abdomen, and moderate hepatomegaly. On anthropometry, his weight was on 50th percentile and height was below 3rd percentile. The infant also had mild motor developmental delay. Laboratory investigation revealed hypoglycemia, hyperlactatemia $(=7)$, mildly elevated liver enzymes (AST $=130 \mathrm{IU} / \mathrm{L}$ [normal $<34 \mathrm{IU} / \mathrm{L}$ ], $\mathrm{ALT}=100 \mathrm{IU} / \mathrm{L}$ [normal: $10-49 \mathrm{IU} / \mathrm{L}]$,) and deranged lipid profile (TGs $=1,722 \mathrm{mg} / \mathrm{dL}$ [normal $<150 \mathrm{mg} / \mathrm{dL}$ ], cholesterol $=275 \mathrm{mg} / \mathrm{dL}$ [normal $<170 \mathrm{mg} / \mathrm{dL}]$ ). However, there was only mild compensated metabolic acidosis $(\mathrm{pH}=7.4$, bicarbonate $=19 \mathrm{mmol} / \mathrm{L} \quad[$ normal $=22-28 \mathrm{mmol} / \mathrm{L}]$, chloride $=98 \mathrm{mmol} / \mathrm{L}[$ normal $=98-106 \mathrm{mmol} / \mathrm{L}])$. The anion gap was normal. Serum potassium, calcium, magnesium, phosphate, and parathormone levels were within normal limits. Spot urine calcium creatinine ratio was elevated (0.75) suggesting hypercalciuria. Twenty-four hours of urinary oxalate levels were in normal range. Stone analysis revealed mixed stone of carbonate, magnesium, and oxalate. received

April 8, 2020

accepted after revision

May 16, 2020
DOI https://doi.org/

10.1055/s-0040-1713630. ISSN 2474-5871.
Copyright (c) 2020 Georg Thieme Verlag License terms KG Stuttgart · New York

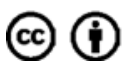




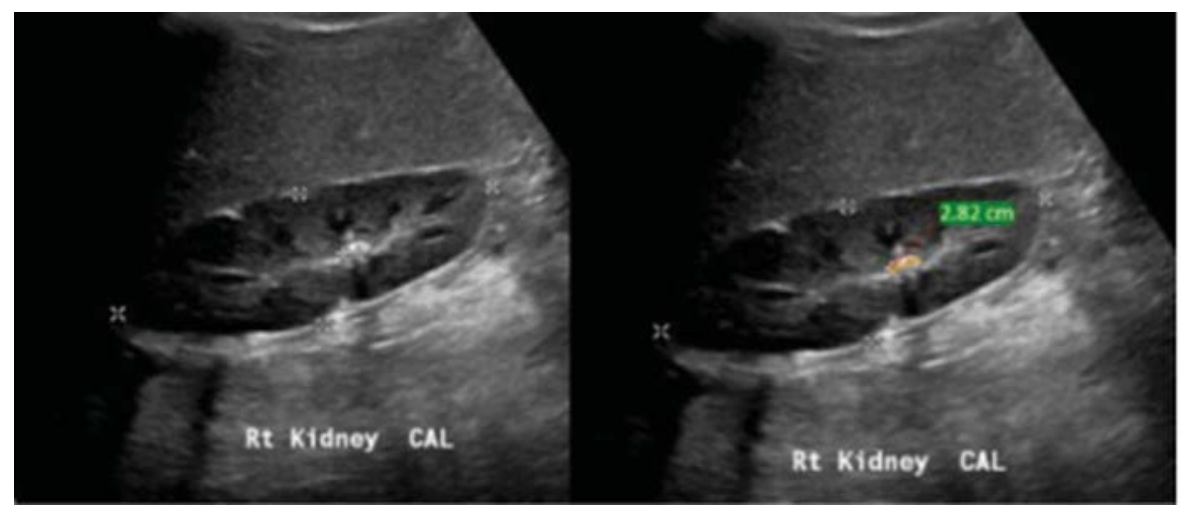

Fig. 1 Ultrasound showing renal calculi in right kidney.

Ultrasound abdomen showed hepatomegaly and bilateral renal calculi with edematous kidney (-Fig. 1). Swollen hepatocytes with abundant glycogen were seen on liver biopsy. The diagnosis of glycogen storage disease type 1a was confirmed by exome analysis which showed homozygous two base pair deletion variant (c.863_864delTC) in exon 5 of the Glucose-6-Phosphatase Catalytic Subunit (G6PC) gene that results in a frameshift and premature mutation. The infant was discharged on corn starch, allopurinol, citrate, thiazide, and dietary advice to prevent hypoglycemia. However, the patient did not have any further episode of symptomatic hypoglycemia but had one episode of hematuria. A repeat Ultrasound abdomen after 3 months showed same size of stones in bilateral kidney ( $\mathbf{- F i g . ~} \mathbf{1}$ ).

\section{Discussion}

Renal stones were the initial presenting feature of type- 1 glycogen storage disease in early infancy in this case. Renal stones in infancy is a rare condition and is caused by deranged metabolism state mainly metabolic acidosis and distal renal tubular acidosis. The most common diseases associated with nephrocalcinosis in infancy are distal renal tubular acidosis, Bartter's syndrome, primary hyperoxalurias, primary hypercalciuria, and drug toxicity. There are case reports of recurrent renal calculi in older age group; however there were no reports in early infancy. Renal complications have been commonly reported in type- 1 GSD as G6PD enzyme is also expressed in kidneys and is associated with excessive glycogen deposits and abnormal metabolic state because of chronic acidosis. Recurrent hypoglycemia leads to excessive production of G6PD that cannot be broken to glucose and goes in other cycle and increases production of lactate, uric acids, and triglycerides. Commonly reported complications are glomerular hyperfiltration, microalbuminuria, nephrolithiasis, and glomerulosclerosis, however renal amyloidosis and Fanconi's syndrome were also seen. ${ }^{2}$ It has also been found that silent glomerular hyperfiltration develops in almost all patients in second decade of life which further progresses to microalbuminuria and later overt proteinuria as age advances. Renal stones were among one of the common complications in older children and it was considered that adequate dietary measures aimed to correct metabolism by avoiding hypoglycemia can prevent stone formation. ${ }^{3}$ Multiple contributing factors like hyperuricemia, chronic acidosis, hypercalciuria, renal tubular acidosis and hypocitraturia are implicated in pathogenesis; however, exact mechanism of nephrolithiasis is not clear in GSD. About $98 \%$ of all the calcium filtered by kidneys is reabsorbed by the tubules, maximum in the proximal tubule (65\%) followed by the thick ascending loop of the loop of Henle $(20-25 \%)$ and distal tubule (8-10\%). Hence, any disturbance in tubular function can lead to hypercalciuria. Urinary citrate works as a calcium chelator and thus reduces the interaction of calcium and oxalate, and also binds to surface of crystals and thus preventing their adhesion to renal epithelial cells. There are case reports that showed hypercalciuria and hypocitraturia increases with age and distal renal tubular acidosis has been implicated in development of nephrolithiasis, ${ }^{4}$ citrate supplementation for preventing renal calcification was found successful in some cases. ${ }^{5}$ It was also reported that with aging, the prevalence of renal involvement increases. ${ }^{6}$ In one case report, multiple metabolic abnormalities including hypercalciuria, hyperoxaluria, hypocitraturia, and hypomagnesuria were found in a 5-year-old child with nephrocalcinosis secondary to GSD type $1 .{ }^{7}$ Our patient did not have any features of renal tubular acidosis, hyperuricemia, or hyperoxaluria; however, mild acidosis and hypercalciuria were present. As stone analysis revealed mixed stone of carbonate, magnesium, and oxalate, chronic acidosis may be implicated in the pathogenesis of stone formation in this case. Despite attainment of good metabolic control after discharge, renal stones did not regress despite allopurinol and citrate treatment. This unique case suggests that the pathogenesis of renal calculi is presumably multifactorial or a part of disease.

Conflict of Interest

None declared.

\section{References}

1 Rake JP, Visser G, Labrune P, Leonard JV, Ullrich K, Smit GP. Glycogen storage disease type I: diagnosis, management, clinical course and outcome. Results of the European Study on Glycogen 
Storage Disease Type I (ESGSD I). Eur J Pediatr 2002;161(Suppl 1): S20-S34

2 Chen YT. Type I glycogen storage disease: kidney involvement, pathogenesis and its treatment. Pediatr Nephrol 1991;5(01):71-76

3 Buist NRM. Inborn errors of metabolism. In: Campbell AGM, McIntosh N, eds. Forfar and Arneil's Textbook of Paediatrics. 4th ed. Edinburgh, Scotland: Churchill Livingstone; 1992:1216-1217

4 Iida S, Matsuoka K, Inoue M, Tomiyasu K, Noda S. Calcium nephrolithiasis and distal tubular acidosis in type 1 glycogen storage disease. Int J Urol 2003;10(01):56-58
5 Reitsma-Bierens WC. Renal complications in glycogen storage disease type I. Eur J Pediatr 1993;152(Suppl 1):S60-S62

6 Lin CC, Tsai JD, Lin SP, Lee HC. Renal sonographic findings of type I glycogen storage disease in infancy and early childhood. Pediatr Radiol 2005;35(08):786-791

7 Yesim Öztürk, Uluç Yis, Alper Soylu, Mehmet Türkmen, Salih Kavukçu, Benal Büyükgebiz. Distal Renal Tubular Dysfunction and Calcium Stone Disease in a Child with Type 1 Glycogen Storage Disease: case report. Official Turkish Society Nephrol 2004;13(03):182-185 